\title{
THE THERAPEUTIC VALUE OF SPORTS ACTIVITY IN NEUROTIC PATIENTS
}

\author{
P. T. KRANIDIOTIS, M.D. \\ Director, Neuropsychiatric Clinic, Piraeus State General Hospital, "Queen Frederika", \\ Piraeus - Greece
}

\begin{abstract}
Five cases of neurotic patients being oriented to sports practice as an additional therapeutic measure are reported in brief. The working mechanisms of sublimation, overcompensation, sharing aggressive guilt within group, displacement, turning aggressive feelings toward one's self, and denial of win used in the canalization of inner needs through sports activity are discussed. The favourable influence of sports activity in the expression of various conflictual tendencies and on the overall neurotic symptomatology is stressed and the usefulness of the dynamic exploration in sports orientation of athletes is concluded.

\section{RESUMÉ}

\section{VALEUR PSYCHOTHERAPIQUE DEL:ACTIVITE SPORTIVE CHEZ NEUROTIQUES}

Cinq cas des malades neurotiques, qui sont été orientés vers la pratique des sports variés, comme un moyen therapeutic surajoutè, sont rapportés. Les méchanismes psychologiques de defense (sublimation, overcompensation, deplacement, etc), qui sont en relation avec le canalization des besoins conflictuels par l'activitè sportive, sont analysès. L'importance favorisante de l'activité sportive sur l'expression des tendances conflictuelles variées (domination, aggressivitè etc) et sur la symptomatologie neurotique elle même est acceptée, et la signification de l'exploration psychodynamique sur l'orientation sportive des athletes est conclue.
\end{abstract}

Sports activities, as a part of a general occupational programme in the treatment of mental patients is a generally adopted routine. In fact, the significance of various kinds of sports in counter balancing latent neurotic traits is well known already, whereas their role in the compensation of the overt neurotic symptoms is insufficiently understood. In this context, we believe that it is always fruitful to proceed in these compensation mechanisms more deeply, in spite of the more or less generally adopted theory of sport psychologists, according to which sport must be viewed as an independent, unique psychosocial phenomenon (Bouet, 1969). We think that dealing with patients practising sport and facing it as a manifestation stemming on their instinctual life, provides a good source of getting certain conclusions eventually applicable to sports psychology. In this perspective we find it profitable to follow up in neurotic patients the evolved psychological processes by which conflictual needs are to some extent gratified by means of an exclusive, specific kind of sport, affording the opportunity of using better the psychological mechanisms of defence.

Five active neurotic patients, non - or ex - athletes, were, on the basis of their principal problems and needs, recommended to practice a specially selected kind of sport, supposed to be able potentially to afford the prerequisites for a better exploitment of various ego mechanisms of defense, and to subserve better the conflictual needs of the patient. The evaluation of the influence of this sport activity in each case was based on the clinical follow-up.

Case 1. H.P., 36, single woman, chemist.

Family dynamics: strong identification and partial introjection of a succesful, domineering, patriarchical father. Great amounts of rivalry and repressed hostility against him, partially turned against herself. Feelings of disdain toward an inadequate mother, covered by overprotective behaviour. Sadomasochistic tendencies.

Childhood: Submissive to father, rebellious to mother. Very competitive and domineering over other children, especially boys. Used to practice horse-riding with success. Fond of chase, "like her father", was prevented from practicing it by him, saying that "chase is not a play for women". Homosexual preoccupations, never realized in practice.

Adulthood: Very successful in her profession. Sexual difficulties and occasional frigidity. Terrifying dreams. Generally good mental health until father's death.

IIIness: After a short depressive phase, severe phobic neurosis with claustrophia and animal-phobia (horses included). Drug and behaviour therapy until she was able to manage her phobias. Recommendation to practice horseriding. She started practicing it in a quasi-compulsive way, and didn't stop until she and her 
horse were exhausted. Satisfactory amelioration. But, insisting preference to jump on male horses only continued to remind her unsolved problems of domination over father-figure.

Comment: Father, as a fearful figure, subconsciously substituted by horses. After horse-father phobias were managed, domination tendencies were assured by deliberately handling the fearful substitute. Main defense mechanisms used: Displacement, turning aggressive feelings toward herself.

Case 2. K.D., 17, male, high school student, only boy of his family.

Family dynamics: Hostility and resentment against oppressive, authoritative mother and nervous, unstable, recessive father. Confusion about male role.

Childhood: Disobedient at home, with hysterical fits. Quarrelsome, aggressive toward other boys in his earlier years, lonely later. Daydreaming with heroic content.

Adolescence: Overtly aggressive and catastrophical at home. Lonely, timid, fearful out of it. Endowed with great speed, rejected his teacher's recommendation to participate in competition. He wanted "to be strong in his arms, not in the legs". Didn't like to participate in football either, as his father was saying, "all footballers were vagabonds".

IIIness: After failing in school great amounts of floating anxiety with severe insomnia, excessive masturbation and aggravation of the catastrophical behaviour. Drug and brief psychotherapy sessions without any benefit. After father's consent, participation in football team was recommended. He became a very good player and scorer. Great amelioration, not only at home, but on the field, also, where he was trying to propagate the spirit of nobility in sports.

Comment: Subconscious rejection of speed competition owing to rebelliousness against father-teacher. Avoidance to compete connected with fears of being rejected, engendered in fight and anticipated win. After doctor - superego - father's permission, canalisation of hostility and especially sharing guilt by being a member of the aggressive football team and facilitation of the male orientation. Main defence mechanisms used: Denial initially, sharing aggression within group, sublimation.

Case 3. P.S., 28, single man, race-driver, only child of his family.

Family dynamics: Ambivalence toward partly introjected father. Self-destructive tendencies and feelings of emotional insecurity.

Childhood: Reared by lenient, recessive grandmother. Mother died when he was two years old. Severe and oppressive father, trying to rear the boy "as strong as a real man," killed in action, when patient was seven. He started to live with an uncle, showing love to the young boy, "only when good degrees were obtained at school". Attempted suicide after failing at school when aged nine.

Adulthood: Drafted as a parachutist, "to be independent". Belonging to the Corps' athletic team as a sprinter had gained many medals, inspite of several minor accidents to which he was prone.

IIIness: After parachute accident resulting in ankle dislocation, various hysterical complaints from the ipsilateral leg. Abandonment of sprint. Soon after, anxiety neurosis with vague fears of death. Obliged to be invalided from the Army, started to spend spare time in driving. After brief psychotherapy with some benefit, recommendation to be oriented to race-driver's profession. Followed our suggestion and had good amelioration.

Comment: Hysterical symptoms, arisen on the occasion of accident preventing him from sprinting, subserved covered fears of failure as he was growing older. Race-driving not engendering this disadvantage, fulfilled father's introjected ideal (real man, dead hero) and afforded the risks subserving self-destructive tendencies. Main defense mechanisms turning aggressive feelings toward himself, sublimation.

Case 4. M.A., 35, married woman, housekeeper, second girl of her family.

Family dynamics: Feelings of being rejected by her mother loving her older sister more. Resentful and blaming her because she was born a girl. Ambivalent feelings toward patriarchical, domineering father, accentuating her subconscious penis envy. Incestuous ideation and dreams.

Childhood: Rebellious to mother, aggressive to older submissive, dull sister. Quarrelsome with rest of female persons of her family (grandmother, servant). Aggressive, not friendly, non cooperative in plays with other children. Nail biting until 11 years old.

Adulthood: Married early. Denial of being pregnant, many abortions. Very promiscuous, continuously changing lovers, ambivalence and guilt. Attempts to work never successful. At last started shoe-business in cooperation with a friend of her husband, an old man, "as reliable as her father". Soon felt in love with him and business blew up. Frigidity. 
IIIness: Right after, various phobias. Couldn't stay alone without the company of her kitten. Long term analytical psychotherapy with slight amelioration. Recommendation to play golf accepted hesitatingly. Very good improvement.

Comment: Fragile compensation ruptured owing to the loss of self-asserting business and guilt activated by incestuous relations. Lying upon assuring qualities of penis' substitutes, like kitten and golf sticks. (Adato, 1964). Main defense mechanisms used: Displacement.

Case 5. J.K., 48, married man, economist, only boy of his family.

Family dynamics: Absence of paternal figure (father lost during the war of 1922). Dependent on domineering anxious mother and 9 years older sister. Hazy ego ideal. Obvious narcissistic tendencies. Latent homosexual traits.

Childhood: Living exclusively with the company of mother and sister. Prevented from going and playing outdoors. "Neighbouring boys didn't belong to their own social class". Initial difficulties in being mixed with school mates were overcame. First student of his class. Seclusive, uncertain, individualistic. Intense daydreaming of domination and social superiority.

Adulthood: Discharged from the army after three months service with the diagnosis of compensation neurosis following postconcussional subjective syndrome. Lover of a ten-years older, rich married woman, from whom he had three children. As consultant of a big construction company, was able to travel continuously over the world. Two years ago married a girl, rather because of common interest in high social life. Wife imposed to be settled anywhere to have home and probably children (in fact, not wanted by him).

IIIness: Right after definite installation growing anxiety with insomnia and excessive drinking. Wife fearing of social exposure conveyed him to the doctor's office in spite of patient's hesitations. Drug and explanatory psychotherapy without any profit. Recommendation to practice sailing, chosen as a means of escape and high society sport in this country. Felt very relieved and stopped excessive drinking.

Comment: Home responsibilities, perspectives of child rearing and dependency evoked feelings of inadequacy and sensibilised latent anxiety. Sailing, under the auspice of mother-wife (secondarily assuming a sham - tender attitude towards this spoiled man) facilitated the desirable escape (without feelings of guilt and inadequacy) in the sea, as a symbolic substitute of mother's bosom. Secondary development of over compensating self-assertion and gratification of the existed narcissistic need for social prestige was helped. Main defense mechanisms used: repression and over compensation.

\section{DISCUSSION AND CONCLUSIONS}

In reviewing the above cases, it can be assumed that psychological mechanišms of defense working in the processes of selection and practising the various sports activities are not unique and vary greatly from case to case. It was found that some of them, like sublimation and overcompensation, were not exclusive in the canalization process of the conflictual problems through sport, as it is usually contemplated by those dealing with deep psychology of the athletes (Hegg, 1969). Perhaps, some mechanisms, like the aforementioned ones, may be much more frequent than others, especially met in mentally healthy sportsmen, and the so-called pathological mechanisms be encountered more often in athletes with prominent neurotic traits. In fact, as it was anticipated in these overt neurotic patients, the so-called mechanisms of psychological defense (sublimation, overcompensation to which we add sharing aggression guilt within group*) were not working before sport practice has started, in contrast to their presence after sport practicing. Really, sublimation and sharing aggression guilt within group (in case 2) and overcompensation (in case 5) were fully exploited after sport practice with excellent clinical improvement. In two cases, where the existed pathological mechanisms displacement (in cases 1 and 4) and turning aggressive feelings toward one's self (in case 1) - were used only, the clinical results were less favourable. Very satisfactory, but not excellent improvement was remarked in the patient of case 3 , where the canalization was based mainly on the turning aggressive feelings toward himself and the sublimation process was secondarily exploited.

Certainly, in some athletes with obvious neurotic traits the presence of psychological mechanisms of defence other than sublimation, overcompensation and sharing aggressive guilt within group is very probable. Thus, displacement seems to be very usual and susceptible to exploitment in sports activity by means of change of the emotionally loaded object or act by

\footnotetext{
* We believe that the beneficial implications of the participation in an aggressive group do not come only from the assurance obtained by the identification with the group. In some subjects the emotional comfort is given through sharing the guilt with the other members of the group, by means of the reactivation of similar defence process developed in infancy among siblings of the same family. That is why, as Bouet says (1969), the sportsmans' desire of win does not necessarily induce guilt, because the conditions of the competition during effort (aggressive activities) are the same for all members of the group. Analogous mechanisms integrated in the team spirit work out in military groups during hostile operations.
} 
another one disguising it symbolically (Deutsch, 1926, Bouet, 1969).

Turning aggressive feelings against one's self, frequently encountered in sports activities (Bouet 1969), presupposes some limits in order to be accepted by the olympic-humanistic attitude in sports. Substantially, it must be directed toward innocuous sports activities, as in case 1, where, not the risk of self, but overfatigue up to exaustion was the ultimate masochistic goal of the patient, a point to be stressed. In this connection we think that, whereas in real athletes in overcoming fatigue a specific role is played volutionally by goal reflex and the operant image which is leading to performance, as Dimitrova has shown recently (1969), it might be not the same in neurotic athletes. We mean that fatigue itself in these subjects may represent the goal of an autopunitive process. (Bouet 1969 p. 198). In fact, this self-directed aggression plays an important role in accident-proneness, (Bouet 1969, Ogilvie and Tutko 1966) existed in case 3 - and in the "near hysterical disregard of risk" met in some kind of sports, like football (Tabrah, 1963). The same thoughts ought to determine the sports psychologist's attitude toward race driving, as practiced by subjects like the patient of our case 3. Two years ago Johnsgard and Ogilvie (1968) found that competitive race drivers appear to be well integrated, stable, reserved, self-assured, self-sufficient individuals with remarkable low anxiety. But we think that is not unwise to juxtapose the abstract thinkers and people tending to reject social customs of Benton's and his co-workers' unsafe drivers sample (1961) and race-drivers like our patient.
As for denial of win (Kranidiotis, 1968) - a synonym of success-phobia of Ogilvie and Tutko (1966) and nikephobia of Antonelli (1463) - this mechanism was noted in the patient of case 2, of which the fears of guilt and rejection, engendered in the achievement attained by aggressive expressivity, were related to his unconscious hostility and resentment toward his father. This dynamic process must underlie in every case of denial of winning and is expected to be present much more often in neurotic athletes. This mechanism may possibly underlie in the cases of accident-proneness also, as we have shown already (1968).

In conclusion, a carefully selected sports activity, suggested by the conflictual needs existing in the given case, is recommended as a positive therapeutic measure in neurotic patients. Moreover, it is concluded that searching for dynamic processes, such as those found in sports activity of the analysed neurotics, should be extended to real athletes also. There is no doubt that beneath elaborate motivations, like need to be at the top, exaggerated self-esteem, strong desire for self-assertion, advanced aggressive tendencies, to mention some of them (Bouet, 1968), or parallel to the so called authentic motivations, like need for play and need for.movement (Antonelli, 1963) some traits of conflictual needs may exist in every healthy person. Therefore, searching for them under the phenomenology of any kind of motivation pattern, is necessary. The practical aspect of this procedure might be the procurement of additional data in the orientation of the given athlete toward this kind of sport that subserves his inner needs.

\section{REFERENCES}

1. ADATTO, C: (1964) On play and the psychopathology of golf. J. Am. Psychoanal. Ass., 1: 12.

2. ANTONELLI, F.: (1963) Psicologia e psicopathologia dello sport. Leonardo, Roma.

3. ANTONELLI, F.: (1969) Psychological problems of top-level athletes Int. J. Sport Psychol., 1: 34.

4. BENTON, J. L., L. MILLS, Jr., K. HARTMAN \& J. CROWN (1961) Auto driver's fitness: An evaluation of useful criteria. J.A.M.A., 176: 419.

5. CRAWFORD LITLLE, J.: (1969) The athlete's neurosis: A deprivation crisis. Acta Psychiat. Scand., $45: 187$.

6. DEUTSCH, H.: (1926) A contribution to the psychology of sport. Int. J. Psychoanal. V. VII.

7. DIMITROVA, S.: (1969) Dependence of voluntary effort upon the magnitude of the goal and the way it is set in sportsmen. Int. J. Sport Psychol., 1: 29.

8. HEGG, J. J.: (1969) Deep psychology in high level athletes Schw. Zeit. Sportmed., 17: 89.

9. JOHNSGRAD, K. W. \& B. C. OGILVIE: (1968) The competitive driver: A preliminary study. J. Sports Med. 8: 87.

10. KRANIDIOTIS, P. T.: (1968) Psychological components and consequences of doping. Hell. Armed Force Med. Rev 2: 176 (in greek).

11. OGILVIE, B. O. \& T. TUTKO: (1966) Problem athletes and how to handle them. Pelham, London.

12. TABRAH, F. L.: (1963) High school football: Valuable sport or sadomasochistic excess. Hawaii Med. I, $23: 106$. 